\title{
Developing a Noise Awareness Rising Web Application within the "Protect your Ears" Project
}

\author{
Dániel Szántó ${ }^{1}$, Attila Zoltán Jenei ${ }^{2}$, Miklós Gábriel Tulics ${ }^{3}$ and Klára Vicsi ${ }^{4}$
}

\begin{abstract}
Noise from our environment is causing evergreater problems such as hearing loss among the young. In many cases, children may be exposed to harmful noise even in the most common places such as schools and events. For this reason, we developed a web application in the frame of the "Protect your Ears" project that aims the teaching of noise awareness. Playing with this web application helps children to be more aware in protecting their hearing. The web application was subjected to a cohort study where a test and control group was separated at an elementary school. The test group was able to use the web application for two weeks during the teaching sessions, while the control group could not. For objective measurement, the pedagogue used questionnaires before and after the examination. Statistical analyses were performed on the values obtained from the questionnaires. At the beginning of the study, we showed that the control and test groups were not heterogeneous at $5 \%$ significance level using the Mann Whitney $U$ test. As a result, there was a significant difference between the preand post-condition for the test group using the Wilcoxon test at the $5 \%$ significance level compering to a control group. From this results, we can conclude that playing with the web application the children in the test group became more aware of the noise in their surrounding and mastered preventive behavior.
\end{abstract}

Index Terms - children hearing loss, noise awareness, web application, Wilcoxon paired test

\section{INTRODUCTION}

According to the World Health Organization (WHO) hearing loss affects millions of people around the world, and it is estimated to be the world's fourth leading disease [1]. Hearing protection is very important as hearing loss affects every area of an individual's life (workplace, social environment, home activities). By identifying the causes of hearing loss preventive behavior can be learned.

\footnotetext{
2,3,4 Department of Telecommunication and Media Informatics, Budapes University of Technology and Economics, Hungary

'email: danielszanto95@gmail.com²email: jenei@tmit.bme.hu

3email: tulics@tmit.bme.hu ${ }^{4}$ email: vicsi@tmit.bme.hu
}

Generally, there are two types of causes of hearing loss: congenital (born with) and acquired. This latter category includes the noise pollution caused by environmental noise [3], [4].

According to WHO approximately 466 million people have hearing loss above $40 \mathrm{~dB}$ Hearing Level (referred to as HL) (30 $\mathrm{dB}$ HL in children), $7.3 \%$ of whom are under 15 years of age [2]. As reported as forecasts, this number could reach the value of 900 million by 2050 . Reports also suggests that $60 \%$ of childhood hearing loss could be prevented with proper prevention and awareness.

In Europe, noise levels have been shown to rise, despite the fact that noise pollution is known to cause health problems [6], [7]. About 75 million people in urban environments are exposed to high levels of noise, of which 20 million are exposed to health hazards [8]. Sleep deprivation caused by environmental noise can occur, with ringing in the ears (tinnitus), increased stress, and various mental illnesses.

Research has shown that values between 70 and $90 \mathrm{~dB}$ (A) (A-weighted decibels) are not uncommon in schools. For example, a noise level test at a primary school in Kiel, Germany, showed that while in classroom work the noise level was $45-50 \mathrm{~dB}(\mathrm{~A})$, during the break in the yard the noise level was $80 \mathrm{~dB}(\mathrm{~A})$, before the teacher entered the classroom it increased to $90 \mathrm{~dB}(\mathrm{~A})$ [9], [10]. At the same time, it has also been found that out-of-school noise can impair school performance. Not only does it interfere with communication and affect school performance, but it can also cause many health problems. Students complain of headaches and sleep problems due to the loud environment, but high noise levels can also be a cause of high blood pressure and circulatory problems [11], [12], [13], [14], [15].

All of this confirms that hearing loss begins to occur at an early age because of environmental factors. However, interventions are needed to prevent hearing loss.

Analyzing the 2014 European Population Health Survey (ELEF), the prevalence of hearing problems among the Hungarian population is $15 \%(\sim 1415$ people) in the surveyed population (9431 people in total) [16]. The proportion of people with severe hearing impairment is $3 \%$ ( 283 people).

A WHO analysis, including Hungary, has shown that untreated hearing loss has a global cost of 750-790 billion American dollars (USD) per year worldwide [17]. 
Developing a Noise Awareness Rising Web

Application within the "Protect your Ears" Project
According to a Hungarian study published in 2017, the National Health Insurance Fund (NEAK - formerly known as OEP) spent 2.011 billion Hungarian forints (HUF) on treating patients with sensorineural and conductive hearing loss [18].

Children and young are at higher risk than adults are. The reason is that they are exposed to the same amount of noise, but their hearing is still intact, so their body is more sensitive. Juvenile hearing loss can affect a child's life, and therefore the importance of hearing protection should be recognized at a young age [19], [20].

In Section 2, we present research already done in rising or survey noise awareness. In Section 3 we describe the structure and the main ideas of the "Protect Your Ears" website, followed by the developed games that aim the teaching of noise preventive behavior. Then the methods of the statistical analysis are presented. Our results are shown in Section 4, followed by the discussion and the future direction in Section 5.

\section{RELATED WORK}

A questionnaire survey has been conducted on noise induced hearing loss, noise pollution and noise protection by Lee Donguk and his colleagues [21]. This questionnaire contained 22 questions in the three categories mentioned above. The questionnaire was completed by 150 people (aged 20-60). $17.3 \%$ of the respondents indicated noise as a serious source of danger, while $80 \%$ of the respondents did not known at all about noise induced hearing loss. This points out that lack of information / awareness can also be significant on the topic.

Based on a proposal from the General Hearing and Communication Center (CHC), a number of activities are being organized in many countries to encourage people to take action against noise [22]. In school education, teachers try to teach the right behavior in the face of everyday noise with the help of readings, lectures, posters and board games.

In Italy, the Acoustics Society of Italy (AIA) is responsible for holding International Noise Awareness Day every year. In the meantime, the emphasis is not only on education, but also on finding solutions to actual noise measurement and various noise-related problems.

In the early 2000s, as part of the Dangerous Decibels Project, the University of Northern Colorado developed a website that aims to educate students and develop positive behaviors to prevent hearing loss [23]. Several problems are highlighted, such as the fact that a North American child may suffer more noise at school than adults at an eight-hour workplace at the factory [24].

An American study has investigated the effectiveness of the Dangerous Decibels prevention program at students of 4 and 7 grades. The research showed that those who attended the preventive lecture had significantly improved their knowledge and behavior regarding the prevention of hearing loss [25].

In Jordan, an attempt was made to assess and raise noise awareness. 245 students (113 females, 132 males, age 21.5 years \pm 2.18 ) were involved from three different universities [26]. Subjects filled out a questionnaire about noise connected daily activities. $9.8 \%$ of the participants stated that they use earplugs to protect themselves against noise. After receiving background material on the harmful effects of noise, as many as $56.3 \%$ said they would use earplugs in the future. This resulted in a significant difference with a two-tailed Chi-square test (paired x2 $=103.0, \mathrm{p}<0.01$ ).

Audio games (AGs) have been developed in the past for noise awareness research [27]. Within this project, a game has been created that contains noises that occur in everyday environments, namely domestic, urban and natural noises. The article did not perform a statistical analysis of the game's effectiveness in this area.

Based on the presented literature, it can be said that little scientific research deals with increasing noise awareness. To the best of our knowledge, there is no research (or statistical study) aimed at increasing children's noise awareness in a playful (web application) form. Of course, there are games designed to protect against noise (board games, computer games, online games), but a scientific study of their effectiveness is not available or is incomplete.

In this study, we aimed to raise children's awareness in the framework of the "Protect Your Ears" project by developing a web application.

The "Protect Your Ears" website was created on the initiative of the Acoustic Inter-Departmental Committee of the Hungarian Academy of Sciences. The aim of the Committee is to raise awareness of the hearing protection of the young generation, in the society's leading organizations and society. It is also important that the protection of children's hearing is currently not regulated in Hungary. The target group of the project is the Hungarian population. However, the basic idea can be transposed to other languages.

In the study, we developed online games for children on the project's website. These will help the child learn the basics of music, localizing and recognizing sound sources. One of these game modules specifically focuses on conscious noise protection and plays a role in developing preventive behavior.

We have created questionnaires for testing noise awareness before and after the use of the web application. We created a control and a test group at a school. The test group used the web application, while the control had not. We tested whether the web application helped the development of noise awareness in the test group compared to the control group with statistical tests.

\section{Demonstration OF ThE "Protect Your Ears" PROJECT}

The main objective is to draw attention for the importance of protecting children's hearing, raise awareness, and deepen the knowledge of the subject that would prevent one from further acquired loss of hearing.

The created website (www.ovdafuled.hu) contains professional quality information that can be used as educational aids at conferences and schools. The website and its contents are available in Hungarian.

The project is represented through other media, such as radio or television interviews, or as a Facebook page. 
The website is a custom-designed website, and its appearance and function can be fully customized to meet current needs. With the help of a web application we provided a tool to measure the sound pressure level, the metadata (environment type, Location, measured sound pressure level, distance from sound source, type of device used for measurement, etc.) of which is stored in a database. The sound pressure level measurement is for information only.

The visitors of the website can distinguish content for children, educators, and anyone who is interested in the topic. Teachers have access to lesson plans, presentations and notes to complement their school lectures. Those interested can be acquainted with basic concepts and mechanisms such as hearing mechanism and noise protection.

To increase children's awareness of environmental noises, a web-based application has been created to provide basic insight into sounds and hearing protection through playful animated tasks.

The development process involved gathering potential functions based on a literature study [28] [29], [30]: the following three aspects were of paramount importance in designing the application.

With easy to use aspect, the user may use the application without supervisor. For this, simplified elements were used. Interactive components have been minimized and text (and voice) guidance has been provided to help keep the game running smoothly.

Using the build-in help function in case getting stuck, the user can get help through the help function of the application to continue playing. In our case, we have placed a video below the game interface where the user plays the game. This will help if your child gets stuck in the game. In addition, there is a help button on the game interface that gives you more detailed information about the certain task.

User interface may draw the child's attention and gaze. In our case, this includes animated elements and sounds. For example, memory cards flip after click on it, keys become pressed on the piano, etc. Pleasant sounds and animations indicate when a child has successfully completed a task.

In addition to the literature, we also sought the views of educators dealing with children. Based on pedagogical opinion and practice the card and board games were successfully used in the educational institution (Dr. Török Béla Kindergarten and Primary School). In addition, the educators may apply audio and game programs that help the child to learn in a playful way. The educators highlighted the importance of emphasizing the function of the ear, the development of hearing loss and prevention ways for the classes.

According to the WHO Ear and Hearing Care Training Material, it is worthwhile to visually facilitate the transfer of knowledge by associating different sounds and noises with different subjects [31].

We compared the user needs with previous suggestions that we have sought from the most credible sources. The user usually looks for the essential interface of the screen, the functions that can be manipulated and keys which can the user move forward or backward.
On this basis, we made a visual hierarchy focusing on size, color, position, shape. For example, green color gives a pleasant impression, the red color something to avoid. Essentials are larger in size and usually centered on the screen. Creating the texts on the screen, we strove for simplicity and clarity.

During the development, the functions and algorithms were introduced into the application. We used HTML5, CSS and JavaScript web technologies.

The text of the tasks and instructions (i.e. the voice guidance) of the application was read by a person with a child-friendly voice, which was recorded with a clip-on condenser microphone. This took place at the Department of Telecommunications and Media Informatics of the Budapest University of Technology and Economics, in the Speech Acoustics Laboratory. This ensured studio-quality sound recording. FL Studio program was used to produce musical sounds, melodies and songs.

Videos (with mp4 extension) have been uploaded about the instructions to help the game experience to the "Protect Your Ears" YouTube channel.

Adobe Photoshop was used to create the graphics. All images and illustrations are free of charge and not protected by copyright.

For a harmonious color scheme, the Adobe Color Wheel tool was used, where you specified a base color to calculate what additional colors would match the theme of the game. Based on this, the main color is bright red, which has become the background color. The overall text color was white, and the highlighted, more prominent contents were given a yellowishgreen color. If the highlighted content has a yellowish-green background, the text will be blue.

After the development, the testing phase was followed by the web application. Manual and automatic testing were done. Automatic testing was done using the JS testing framework. The developer did alpha testing, while independent university students did beta testing.

The children's interface created with this process included three games. The first game module is a hearing training, where the child can become familiar with sounds in a classroom and in a general room. He or she can localize its sources and recognize them by voice.

In the second game module, several difficulty levels can be distinguished. At the beginner level, the child can choose from 3 possible options for what sound was emitted. He or she can play an advanced memory game where the pairs should be found based on the sources and its sounds. On a difficult level, the child can categorize and sort hazardous and non-hazardous audio sources according to the $\mathrm{dB}$ scale.

In the third module, the player can also acquire basic music skills at several difficulty levels. Get started with getting to know the music sounds. The user can practice advanced song recognition by selecting from three options after listening the song. Finally, he or she can play an actual song on the virtual piano at the most difficult level.

The games can be found under the following link: http://www.ovdafuled.hu/gyermek.php. 
Developing a Noise Awareness Rising Web

Application within the "Protect your Ears" Project
A convenient feature is that the game volume can also be adjusted using the volume icon indicated in the lower left corner of the figure.

The game start screen shows the name of the game and a description of the task, which is read out loud automatically. If the user does not want this auto play to occur, this can be turned off.

For some tasks, the player can also get help, where he can find leading information on how to solve the task (HELP button) and also the uploaded videos can be a guidance.

At the end of the game, an animated greeting card rewards the player. This card is not only motivating, but also provides an opportunity to restart the game or select additional games. This is encouraging, as the child will have a sense of success and will probably want to try more games as well.

Of the three modules, the second one aims to raise awareness for hearing protection. It introduces the child to the noisy sounds in its environment. Herewith it makes the child aware that he or she should avoid it.

The effectiveness of the web application for raising awareness of hearing protection was investigated in Dr. Török Béla Kindergarten and Primary School with an experimental layout, which will be discussed in the next section. The study was conducted with the consent of parents and educators.

\section{STATISTICAL EXPERIMENTS}

In the experiment, two groups were distinguished: the test group and the control group. In terms of hearing condition, both hearing impaired and normal hearing members were present in both groups.

The sample is not representative, as the sample is made by students of only one school, so no conclusions can be drawn for all children in Hungary, but as a local result.

The composition of the two groups is shown in Table 1 .

TABLE 1

THE TEST AND CONTROL GROUP COMPOSITION (UNIT: PERSON)

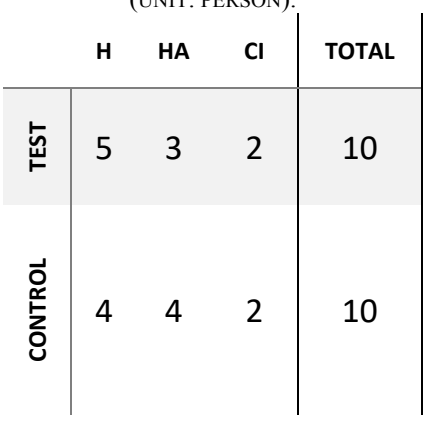

Each group consisted of 10-10 children, 6 boys and 4 girls. In the test group, 5 had healthy (normal) hearing $(\mathrm{H}), 3$ had hearing aids (HA) and 2 had cochlear implants (CI). In the control group, this distribution was 4-4-2. The average age of the test group was 10.2 years and the control group was 10.0 years.
The person conducting the survey is a surdopedagogue and speech therapist. During the pedagogical sessions, the educator has integrated the use of hearing application games for the test group in the curriculum. Based on this, the children used the software four days a week for an average of 15 minutes for two weeks.

A questionnaire was applied to assess children's noise awareness and preventive behavior. We designed the structure of the questionnaires in such a way that it would not be too complicated for the children, but at the same time provide enough information to get answers to the questions asked in the hypothesis.

Research focuses mainly on creating questionnaires on noise exposure for young adults and children [32], [33], but there is little research regarding noise awareness. For this reason, the questions of our questionnaire was based on the knowledge materials of the website working on the topic [23]. The compiled questions were also studied by experts, and then the questionnaire containing the three groups of questions was created.

In the first group of questions, sound sources could be identified that may have harm effect on hearing ("Task 1: Mark the ones listed that may be harmful to your ears."). In the second group of questions, it had to be decided which of the listed objects / events had the highest noise level ("Task 2: Choose from the three objects which has the highest noise level."). In the third group of questions, we collected situations that occur in everyday life where the child's hearing may be impaired. We asked about the decisions made in these situations ("Task 3: When should you protect your ears (with earplugs, earmuffs, hearing aids)").

The questionnaire examines general noise awareness, which were completed as follows: The surveyor reads out the questions and the child's answers are recorded on the printed test paper. Two questionnaires were made (A and B), which were the same on their structure and question types, differing only in the questions itself. Questionnaire A was completed by the children before the experiment, and B after the experiment. In both tests, points were obtained for correct answers, with a maximum of 17 points. On this basis, children's awareness was quantified.

Data was processed anonymously. Non-parametric statistical tests were used to examine these discrete values. The MannWhitney U test was used to examine the homogeneity of the two groups. In both groups, Wilcoxon paired test was used to examine the before and after condition.

Whole scores could be given for the questionnaires.

\section{A. Mann-Whitney U Test}

The Mann Whitney U test helps to compare the distribution of two independent sets. It has the advantage that it is applicable to a non-normally distributed dataset [34].

The null hypothesis of the test states that the two test sets originate from the same population. In other words, the two sets are homogeneous and have the same distribution. In our term 
the null hypothesis is the following: There is no significant difference between control and test group performances.

Using the two-sided test, the alternative hypothesis can be formulated so that the test and control groups' performances differ from each other significantly. By accepting the alternative hypothesis, the null hypothesis is rejected.

Two-tailed statistical analysis was performed at 5\% significance level.

\section{B. Wilcoxon Paired Test}

Related cohorts were tested using the Wilcoxon paired test. The distribution of the sample sets is assumed to be the same. This is used to test the values of the scores at pre and post condition [35].

Define the null hypothesis as there is no difference between the median values of the two sample sets. In this case, the sample sets are the pre- and post-performance on the given questionnaire. Because of this, the alternative hypothesis can be draw up as there is a significant difference between the median values of the two sample sets.

Differences in pre- and post-performance (pre - A, post - B questionnaire) can be investigated separately for the control and the test groups with the paired Wilcoxon test.

Two-tailed statistical analysis was performed at 5\% significance level.

\section{RESULTS}

Table 2 shows the scores of the two groups on the "A" and "B" questionnaires. We can see from the scores of questionnaires that the average of the points increases in both groups (except for one or two children). However, both types of questionnaire were designed with the same difficulty. This suggests that contact with the subject is capable of producing a small (non-significant) increase in noise awareness.

TABLE 2

SCORES OF QUESTIONNAIRE "A" AND "B".

\begin{tabular}{|c|c|c|c|c|}
\hline $\begin{array}{c}\text { Number } \\
\text { of child }\end{array}$ & \multicolumn{2}{|c|}{ Control } & \multicolumn{2}{c|}{ Test } \\
\hline & "A" & "B" & "A" & "B" \\
\hline 1 & 7 & 8 & 10 & 15 \\
2 & 7 & 11 & 16 & 16 \\
3 & 6 & 10 & 9 & 15 \\
4 & 11 & 12 & 11 & 16 \\
5 & 10 & 10 & 5 & 16 \\
6 & 14 & 16 & 7 & 16 \\
7 & 12 & 12 & 10 & 16 \\
8 & 11 & 14 & 8 & 16 \\
9 & 9 & 13 & 11 & 12 \\
10 & 6 & 5 & 5 & 17 \\
\hline
\end{tabular}

\section{A. Mann-Whitney U Test Results}

Testing the scores of the "A" questionnaires in the control and test groups, we found that they did not differ significantly (Mann-Whitney U test). In other words, the control and test groups are not heterogeneous at $5 \%$ significance level. (U value $=53.500, \mathrm{Z}$ value $=0.265$ )
We also compared the score differences (after - before condition) of the two groups with a single test, because it could be more adequate for small groups ( 10 children). Table 3 shows the score differences.

TABLE 3

AFTER AND BEFORE QUESTIONARIES' SCORE DIFFERENCES FOR BOTH THE CONTROL AND TEST GROUPS PARTICIPANTS.

\begin{tabular}{|c|c|c|}
\cline { 2 - 3 } \multicolumn{1}{c|}{} & Control & Test \\
\hline $\begin{array}{c}\text { ID of } \\
\text { participants }\end{array}$ & $\begin{array}{c}\text { B-A score } \\
\text { diff. }\end{array}$ & $\begin{array}{c}\text { B-A score } \\
\text { diff. }\end{array}$ \\
\hline 1 & 1 & 5 \\
2 & 4 & 0 \\
3 & 4 & 6 \\
4 & 1 & 5 \\
5 & 0 & 12 \\
6 & 2 & 10 \\
7 & 0 & 7 \\
8 & 3 & 8 \\
9 & 4 & 6 \\
10 & -1 & 12 \\
\hline
\end{tabular}

We found that they differ significantly (Mann-Whitney U test). In other words, after two weeks the control and test groups are not homogeneous at 5\% significance level. ( $\mathrm{U}$ value $=$ 92.000, $Z$ value $=3.175$ ) .

\section{B. Wilcoxon Paired Test Results}

Using the mean and standard error of the signatures of the test group, the value of $t$ is 5.780 . At $5 \%$ significance and 9 degrees of freedom, the critical t value is 2.260 [36]. Accordingly, we reject the null hypothesis and accept the alternative hypothesis for the test group. In other words, the noise awareness of the test group was significantly increased by the application (at 5\% significance level).

In the control group, $\mathrm{t}$ is 2.249. Similarly, the critical $\mathrm{t}$ value is 2.262 [37] at 5\% significance level. Based on this, we accept the null hypothesis. That is noise awareness did not change significantly in the control group.

\section{CONCLUSION}

Literature research shows that noise awareness rising games/applications already exist. However, their scientific basis is still indigent. Although there are calls for noise-induced hearing loss on more and more platforms (for example International Noise Awareness Day).

In this study, we developed a web application within the "Protect Your Ears" project, that helps children increase their noise awareness and prevention methods in a playful form.

Different needs and implementation options were considered during the development process. Finally, three types of games were created for the website (www.ovdafuled.hu). Of these, one specifically served to raise noise awareness.

To test the completed application, we conducted a cohort study in Dr. Török Béla Kindergarten and Primary School. Accordingly, a test and control group was separated. The test group could use the application for two weeks, while the control group could not. 
Developing a Noise Awareness Rising Web

Application within the "Protect your Ears" Project
Through the questionnaires, we examined whether the web application significantly improves noise awareness in the test group or not. The homogeneity of initial setup was examined beforehand and resulted that the two study groups were sampled from the same population.

Wilcoxon and Mann-Whitney U (for score differences) tests showed a significant difference in the test group's performance in developing noise awareness. This was not observed in the control group. We have seen that familiarity with the subject that can increase noise awareness, but without using the web application the improvement was not significant.

So it can be said the use of developed games have helped to raise noise awareness. This highlights the importance of developing hearing protection games. This will allow the child to playfully learn about the ear protection and the importance of noise. While just mentioning information about the topic, noise awareness increase will be less effective.

Based on this study, we cannot draw conclusions understandably - for the entire population. That is why it is necessary for validation, detailed professional review in order to form a more accurate opinion about its effectiveness. In doing so, it is worthwhile to increase the number of samples, to ensure representativeness, and to include other parameters that may affect the phenomenon (living environment, lifestyle, etc.). It is worth examining healthy as well as hearing-impaired children separately (ensuring homogeneity), and it may be interesting to assess a mixed arrangement from these groups in order to determine the correlation as accurately as possible. Instead of a possible questionnaire survey, it is worthwhile to examine awareness in other ways, as the collection of questionnaire data may not reflect the decisions made in real life. In this context, it would become possible to demonstrate whether the application is in fact able to raise awareness among children.

In the future, it may worth expanding the variety of the games or implementing a personalized recommendation (suggesting a suitable game in case of an age or problem option). Also, there is a need to examine this study with study groups of more participants.

Although this would require new, more comprehensive research, realizing this idea is likely to be more effective in raising awareness among children while having fun.

\section{ACKNOWLEDGMENT}

The authors would like to thank Mónika Gyurkovics and her team from the Dr. Török Béla Kindergarten and Primary School for their help and guidance in creating the child interface and conducting the research. We would like to highlight Dávid Babiák's contribution towards creating the website. We would also like to thank Hala Muhanna for contributing with her voice to the application.

\section{REFERENCES}

[1] World Health Organization. (2018). Addressing the rising prevalence of hearing loss. World Health Organization. https://apps.who.int/iris/handle/10665/260336. License: CC BY-NC-SA 3.0 IGO

[2] World Health Organization, 'Deafness and hearing loss', 2019. [Online]. Available: https://www.who.int/news-room/fact-sheets/ detail/deafness-and-hearing-loss. [Accessed: 30-Jan-2020].

[3] American Speech-Language-Hearing Association (ASHA), 'Causes of Hearing Loss in Children'. [Online]. Available: https://www. asha.org/public/hearing/Causes-of-Hearing-Loss-in-Children/. [Accessed: 31-Jan-2020].

[4] L. L. Cunningham and D. L. Tucci, 'Hearing Loss in Adults', N. Engl. J. Med., vol. 377, no. 25, pp. 2465-2473, Dec. 2017, DoI: $10.1056 /$ NEJMra1616601.

[5] S. F. Carroll YI, Eichwald J, 'Vital Signs: Noise-Induced Hearing Loss Among Adults - United States 2011-2012', 2017. Dor: $10.15585 / \mathrm{mmwr} . \mathrm{mm} 6605 \mathrm{e} 3$

[6] European Commission, 'Noise pollution in the EU'. [Online]. Available: https://ec.europa.eu/environment/basics/healthwellbeing/noise/index_en.htm. [Accessed: 25-Jan-2020].

[7] European Environment Agency, 'Number of people exposed to average day-evening-night noise levels (Lden) $\geq 55 \mathrm{~dB}$ in Europe', 2019. [Online]. Available: https://www.eea.europa.eu/data-andmaps/daviz/number-of-people-exposed-to-8\#tab-googlechartid_ chart_21. [Accessed: 27-Jan-2020].

[8] European Environmental Agency, 'Noise in Europe 2014', Luxembourg, 2014. Dor: 10.2800/763331

[9] L.-B. Johann-Wolfgang, E. Kerstin, and E. Angelika, Lärm und Gesundheit. Köln (Noise and health), Bundeszentrale für gesundheitliche Aufklärung (BZgA), 2001. ISBN 3-933191-53X

[10] Téglás Zsolt Gábor, 'Iskolai zajártalmak', Pedagogical Periodicals, 2004. [Online]. Available: https://folyoiratok.oh.gov.hu/ujpedagogiai-szemle/iskolai-zajartalmak. [Accessed: 22-Dec-2019].

[11] K. Eysel-Gosepath, T. Daut, A. Pinger, W. Lehmacher, and T. Erren, 'Effects of noise in primary schools on health facets in German teachers', Noise Heal., vol. 14, no. 58, pp. 129-134, May 2012,

[12] B. Shield and J. Dockrell, 'The Effects of Noise on Children at School: A Review', Build. Acoust., vol. 10, pp. 97-116, Jun. 2003, DoI: $10.1260 / 135101003768965960$.

[13] B. Shield and J. Dockrell, 'The effects of environmental and classroom noise on the academic attainments of primary school children', J. Acoust. Soc. Am., vol. 123, pp. 133-144, Feb. 2008, DoI: $10.1121 / 1.2812596$.

[14] G. Evans and S. Lepore, 'Nonauditory Effects of Noise on Children: A Critical Review', Child. Environ., vol. 10, pp. 31-51, Jan. 1993

[15] S. Cohen, G. W. Evans, D. S. Krantz, and D. Stokols, 'Physiological, motivational, and cognitive effects of aircraft noise on children: Moving from the laboratory to the field', Am. Psychol., vol. 35, no. 3, pp. 231-243, 1980, Dor: 10.1037/0003-066X.35.3.231.

[16] Központi Statisztikai Hivatal (KSH), 'A 2014-ben végrehajtott Európai lakossági egészségfelmérés eredményei’, 2018. ISBN 978963-235-508-5

[17] World Health Organization, 'Global costs of unaddressed hearing loss and cost-effectiveness of interventions', 2017. ISBN 978-92-4151204-6

[18] T. Gazsó, A. Sebestyén, D. Endrei, and I. Boncz, 'PSS4 Health insurance burden of conductive and sensorineural hearing loss in Hungary: A nationwide, real world treatment cost of illness study', Value Heal., vol. 22, pp. S363, May 2019, DoI: $10.1016 /$ j.jval.2019.04.1776.

[19] L. C. Erickson and R. S. Newman, 'Influences of Background Noise on Infants and Children', Curr. Dir. Psychol. Sci., vol. 26, no. 5, pp. 451-457, Oct. 2017, Dor: 10.1177/0963721417709087. 
[20] G. W. Evans, P. Lercher, M. Meis, H. Ising, and W. W. Kofler, 'Community noise exposure and stress in children', J. Acoust. Soc. Am., vol. 109, no. 3, pp. 1023-1027, 2001, Dor: 10.1121/1.1340642.

[21] Lee Donguk, Yu Jyaehyung, Han Woojae, 'Evaluation and Analysis of Awareness in Noise-induced Hearing Loss Using Survey" The Journal of the Acoustical Society of Korea. 34. 274-281., 2015. Dor: 10.7776/ASK.2015.34.4.274.

[22] Mariconte Raffaele, Luzzi Sergio, Natale, Rossella, "Instruments, methods and activities for noise awareness", in the 22nd International Congress on Sound and Vibration, Florence, Italy, 2015.

[23] Dangerous Decibels, 'Dangerous Decibels'. [Online]. Available: http://dangerousdecibels.org/. [Accessed: 31-Jan-2020].

[24] WHO Programme for the Prevention of Deafness and Hearing Impairment. (1998). Prevention of noise-induced hearing loss: report of an informal consultation held at the World Health Organization, Geneva, on 28-30 October 1997. World Health Organization. https://apps.who.int/iris/handle/10665/65390.

[25] S. E. Griest, R. L. Folmer, and W. H. Martin, 'Effectiveness of "dangerous decibels," a school-based hearing loss prevention program', Am. J. Audiol., vol. 16, no. 2, pp. 165-182, 2007, DOI: $10.1044 / 1059-0889(2007 / 021)$.

[26] Alnuman Nasim, Ghnimat Talha, 'Awareness of Noise-Induced Hearing Loss and Use of Hearing Protection among Young Adults in Jordan' International Journal of Environmental Research and Public Health. 16. Dor: 10.3390/ijerph16162961.

[27] E. Rovithis, A. Floros, A. Mniestris and N. Grigoriou, "Audio games as educational tools: Design principles and examples," 2014 IEEE Games Media Entertainment, Toronto, ON, 2014, pp. 1-8, DoI: 10.1109/GEM.2014.7048083.

[28] S. Katie and N. Jakob, 'Children's UX: Usability Issues in Designing for Young People', Nielsen Norman Group, 2019. [Online]. Available: https://www.nngroup.com/articles/childrens-websitesusability-issues/. [Accessed: 01-Feb-2020].

[29] T. Nousiainen and M. Kankaanranta, 'Exploring Children's Requirements for Game-Based Learning Environments', Adv. Human-Computer Interact., vol. 2008, pp. 1-7, 2008, DoI: $10.1155 / 2008 / 284056$.

[30] L. Darling-Hammond, L. Flook, C. Cook-Harvey, B. Barron, and D. Osher, 'Implications for educational practice of the science of learning and development', Appl. Dev. Sci., vol. 0, no. 0, pp. 1-44, 2019, Dor: 10.1080/10888691.2018.1537791.

[31] World Health Organization, 'Primary ear and hearing care training resource', World Heal. Organ. Geneva, pp. 1-90, 2006, DoI: $10.1007 / \mathrm{BF} 02887432$.

[32] Johnson TA, Cooper S, Stamper GC, Chertoff M. 'Noise Exposure Questionnaire: A Tool for Quantifying Annual Noise Exposure', J Am Acad Audiol. 2017;28(1):14-35. Dor: 10.3766/jaaa.15070

[33] Penafiel Emie, 'Developing a Questionnaire to Assess Noise Exposure in Children and Teens', Thesis, Department of Speech and Hearing Science Honors Theses, Ohio State University, Colombus, Ohio, United States, 2007.

[34] N. Nachar, 'The Mann-Whitney U: A Test for Assessing Whether Two Independent Samples Come from the Same Distribution', Tutor. Quant. Methods Psychol., vol. 4, no. 1, pp. 13-20, 2008, DoI: 10.20982/tqmp.04.1.p013.

[35] E. Whitley and J. Ball, 'Statistics review 6: Nonparametric methods', Crit. Care, vol. 6, no. 6, pp. 509-513, 2002, doi: 10.1186/cc1820.

[36] Ted Hessing, 'Z Scores (Z Value) \& Z Table \& Z Transformations', sixsigmastudyguide.com. [Online]. Available: https:// sixsigmastudyguide.com/z-scores-z-table-z-transformations/. [Accessed: 02-Feb-2020].

[37] Six Sigma Material, 't-distribution (t-tests)', https://www.six-sigmamaterial.com/. [Online]. Available: https://www.six-sigma-material. com/t-distribution.html. [Accessed: 03-Feb-2020].

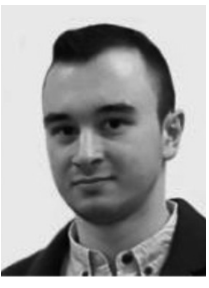

Dániel Szántó was born in Gyöngyös, Hungary in 1995. He graduated from the Semmelweis University with Bachelor's Degree in Health Care Management (2018 - Hungary, Budapest). He also graduated from the Budapest University of Technology and Economics with Master's Degree in Biomedical Engineering (2020 - Hungary, Budapest).

Since March 2020, he has been software developer in Hatvan, Hungary. His diploma work focused on Developing a Noise Awareness Rising Web Application. In 2017, he participated in Student Research Societies of Semmelweis University with the work of Mobile health application development. He won the National Higher Education Scholarship in 2017 and the Hungarian Republic Scholarship in 2016.

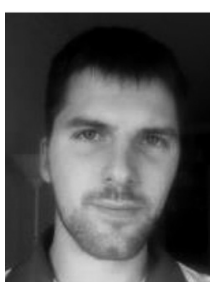

Attila Zoltán Jenei was born in Debrecen, Hungary in 1995. He is graduated at the Budapest University of Technology and Economics as Biomedical Engineer (Master's Degree, 2020). Since January 2020, he has been a research assistant in the Laboratory of Speech Acoustic, Department of Telecommunications and Media Informatics, Faculty of Electrical Engineering and Information Technology. His research and diploma work focuses on the speech-based diagnostic opportunities of depression, Parkinson's disease and different voice disorder groups. In 2019, he participated in Student Research Societies of Budapest University of Technology and Economics with the work of Automatic speech-based detection of depression with 2D convolutional networks.

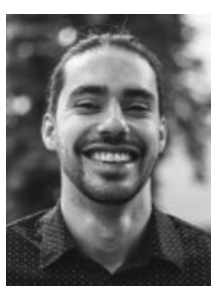

Miklos Gabriel Tulics was born in Baia Mare, Romania, on Aug. 15, 1988. He is currently a technical assistant and a Ph.D. candidate at the Laboratory of Speech Acoustics, Budapest University of Technology and Economics, focusing on automatic speech recognition, machine learning, pathological voice disorder recognition and noise awareness. He earned his Master's degree in Electrical Engineering in 2015. Tulics has been working for the Department of Telecommunications and Media Informatics, Budapest University of Technology and Economics since 2013.

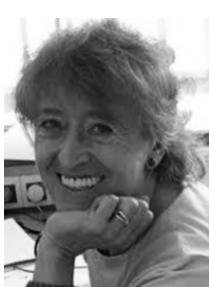

Klára Vicsi DSc Ph.D. is currently a lead research professor and was the Chief of the Laboratory of Speech Acoustics of the Department of Telecommunications and Media Informatics at Budapest University of Technology and Economics from 2002 until 2018. She earned her Master's degree at the Loránd Eötvös University of Sciences, Budapest in 1966-1971.

She earned her DSc degree at the Hungarian Academy of Sciences in 2005, her PhD degree at the Technical University of Budapest in 1992, and her Doctor's degree at Loránd Eötvös University of Sciences in 1982. She has worked as a researcher and lecturer, participated in conferences and congresses in several countries such as Germany, California USA, Finland and Poland. She is responsible for the organization of many international conferences, workshops and summer schools. She holds project manager and participant member status in several international research projects such as: Contact person, of CLARIN, FLaReNet, ELSNET. She is the leader of the Acoustical Complex Committee of the Hungarian Academy of Sciences, a Member of ISCA and a member of the scientific board of journals. She has more than 122 publications in peerreviewed journals, 67 refereed conference proceedings and is the owner of three patents. 